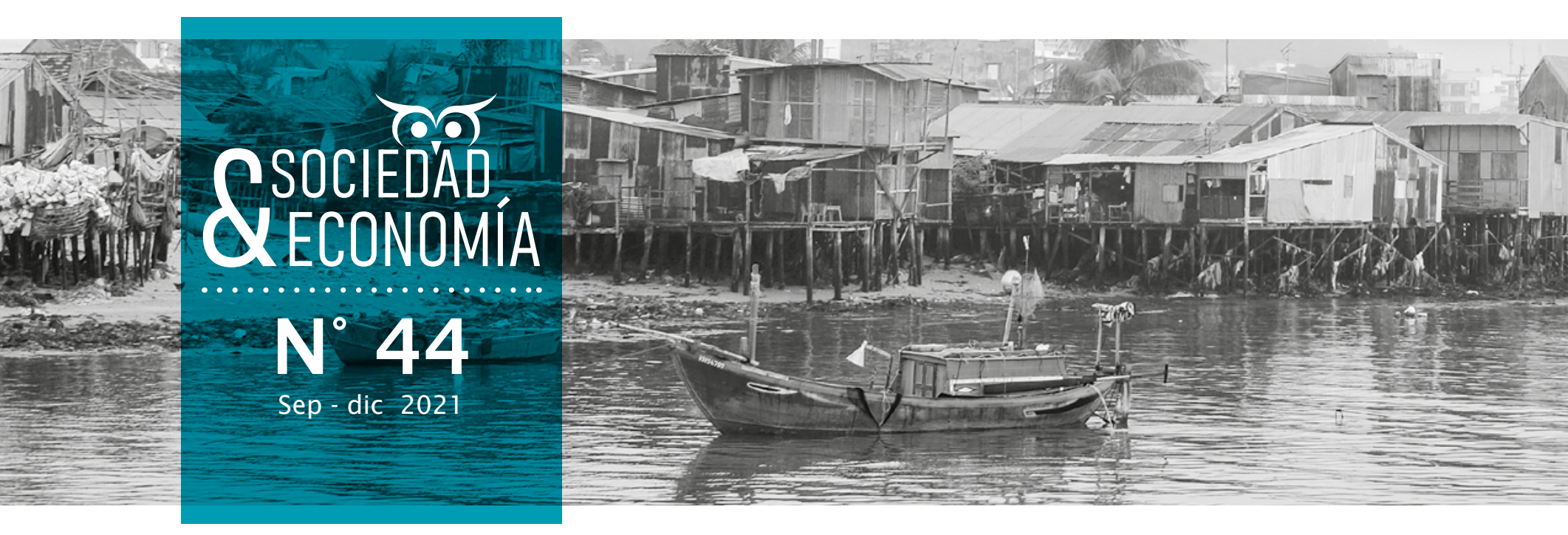

\title{
Análisis de las técnicas valuatorias colombianas para las viviendas palafíticas del Pacífico. Caso Buenaventura, Valle del Cauca
}

Analysis of Colombian Valuation Techniques for The Palafitic Housing of The Pacific. The Case of Buenaventura, Valle del Cauca

María Alejandra Bermúdez-Ayala ${ }^{1}$

Universidad Distrital Francisco José de Caldas, Bogotá, Colombia

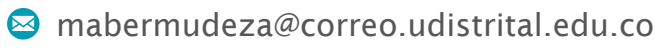

(D) https://orcid.org/0000-0002-5905-3436

\section{Juan Camilo Castro-Ortiz ${ }^{2}$}

Universidad Distrital Francisco José de Caldas, Bogotá, Colombia

지castroo@correo.udistrital.edu.co

(1) https://orcid.org/0000-0001-8220-3837

\section{Johan Andrés Avendaño-Arias 3}

Universidad Distrital Francisco José de Caldas, Bogotá, Colombia

@ jaavendanoa@correo.udistrital.edu.co

(D) https://orcid.org/0000-0002-7193-2070
Recibido: 04-02-2021 Aceptado: 24-05-2021 Publicado: 15-09-2021

1 Estudiante de pregrado en Ingeniería Catastral y Geodesia.

2 Estudiante de pregrado en Ingeniería Catastral y Geodesia.

3 Doctor en Geografía. 


\title{
Resumen
}

El presente artículo consta del análisis reflexivo acerca de los procedimientos valuatorios colombianos en el contexto de la vivienda palafítica de la región del Pacífico, más exactamente en el municipio de Buenaventura, Valle del Cauca. Se aborda el desarrollo territorial desde los primeros establecimientos representativos en la región hasta el progreso y persistencia de las tipologías arquitectónicas tradicionales, así como las características más significativas de la actual estructura de viviendas palafíticas. Se contrastó la normativa valuatoria vigente para un acercamiento a los métodos acordes a esta tipología; como primera aproximación, los métodos costos de reposición y capitalización de rentas posibilitan asignar un valor económico a la tradicional vivienda del Pacífico. No obstante, es necesario enfrentar el reto para considerar por completo esta estructura constructiva de forma legal, además considerar el valor cultural presente en el diseño arquitectónico como respuesta a la valoración patrimonial que representa para la región en general.

Palabras clave: hábitat; valoración; precio; autoconstrucción.

\begin{abstract}
This article presents a reflexive analysis of the Colombian valuation procedures in the context of the palafitic housing in the Pacific region, specifically in the municipality of Buenaventura, Valle del Cauca. The territorial development from the first representative establishments in the region to the progress and persistence of the traditional architectural typologies, as well as the most significant characteristics of the current structure of pile dwellings are approached. The current valuation regulations were contrasted for an approach to the methods according to this typology; as a first approximation, the replacement cost and rental capitalization methods make it possible to assign an economic value to the traditional housing of the Pacific. However, it is necessary to confront the challenge of considering this constructive structure in a lawful way, as well as to consider the cultural value present in the architectural design as a response to the patrimonial valuation that it represents for the region in general.
\end{abstract}

Keywords: hábitat; valuation; price; self-construction.

\section{Financiación}

Este artículo es resultado de un proyecto no financiado realizado en el semillero Pensamiento Espacial y Territorial del grupo de investigación NIDE de la Universidad Distrital Francisco José de Caldas.

\section{Conflicto de interés}

Los autores declaran no tener ningún conflicto de interés en la publicación de este artículo. valuatorias colombianas para las viviendas palafíticas del Pacífico. Caso Buenaventura, Valle del Cauca. Sociedad y economía, (44), e10710980. https://doi.org/10.25100/sye.v0i44.10980 
Sociedad y Economía N 44 (Sep - dic 2021) / e-ISSN: 2389-9050 / e10710980

Análisis de las técnicas valuatorias colombianas para las viviendas palafíticas del Pacífico. Caso Buena-

ventura, Valle del Cauca

\section{Introducción}

La región Pacífica de Colombia, en el costado occidental, caracterizada por la presencia de pueblos de agua o palafíticos, representa en su máxima expresión la producción social del espacio, en un proceso de adaptación a las condiciones biofísicas, como una manera de identidad cultural. La edificación de viviendas acuáticas ${ }^{4}$, como se conoce en el resto del mundo esta tipología constructiva, por su cercanía a zonas cubiertas de agua, configura una manera de adaptabilidad en las regiones, al ser capaces de flotar a orilla de los ríos o espejos (García, 2019). Una vivienda palafítica se ha de entender "como una extensión del mangle casi que simbiótica, que junto con los demás palafitos crecen a su alrededor, afinca sus raíces sobre las aguas y por debajo de ellas. Para luego multiplicarse en torno al tronco central, al tronco materno" (Servigna, 2007, p. 158).

La vivienda palafítica de las comunidades negras del Pacífico colombiano en realidad constituye un elemento cultural que expresa una parte fundamental de la identidad regional. De hecho, este tipo de vivienda expresa un conocimiento local a un buen detalle de los factores climáticos, los ciclos del agua y el conocimiento de los recursos forestales, por tanto, se convierte en una construcción que las comunidades han generado para convivir en una de las zonas más biodiversas del mundo (Garcés, 2016). La ciudad de Buenaventura se encuentra en el occidente de Colombia (Figura 1) y es de vital importancia para el país al ser denominada Distrito Especial, Industrial, Portuario, Biodiverso y Ecoturístico, como una síntesis de su situación geográfica y de ser el principal puerto de Colombia, por medio del cual se conecta con el resto de la economía del mundo. Además de contribuir significativamente a la economía de la región y el país, es el núcleo urbano con mayor población del $\mathrm{Pa}$ -

4 Las teorías actuales de viviendas acuáticas parten de construcciones sobre el agua que se dividen en cuatro categorías principales: sobre montículos, anfibias, flotantes y palafíticas (García, 2019). Esta última clasificación es la base central del presente trabajo. cífico colombiano, como expresión territorial de la construcción de hábitat afrodescendiente posterior a la época colonial. Tiene un litoral variado, con varios tipos de elementos geomorfológicos que van desde cerros con acantilados, extensas llanuras de manglares, hasta islas barreras con frentes de playa que forman la mayor parte del litoral (Gallego y Selvaraj, 2019). Todo un paraíso biofísico excepcional.

Las viviendas palafíticas en el territorio colombiano, principalmente aquellas de origen colonial, en tanto expresiones de la reterritorialización de la población esclavizada, corresponden a una adaptación constructiva, que permite una buena interacción entre las condiciones climatológicas del lugar de asentamiento y sus habitantes, pero también en cierta medida son la materialización de la añoranza de las formas de vida de los territorios de origen de sus ancestros africanos. Esta tipología de vivienda se acentúa en lugares donde la estructura biofísica dominada por las fuerzas del agua (Tumaco, Quibdó, Buenaventura, etc.), se convierte en la principal fuente de sustento diario, vinculado con la pesca y los recursos forestales. Al tiempo, se constituyen como los principales abastecedores de materiales constructivos, resistentes a la interacción con el agua (Ávila y Toro, 2003). Por consiguiente, comprender social, económica y culturalmente, para establecer saberes más amplios sobre los asentamientos palafíticos de esta zona, por medio de los métodos valuatorios, se encuentra en el trasfondo de esta reflexión.

Estas técnicas constructivas, que no son nada contemporáneas ni excepcionales de Colombia, se configuran ahora incluso como nuevas alternativas que pueden convertirse en maneras de adaptación a los efectos del cambio climático, mientras se vislumbra el aprovechamiento potencial de la zona (García, 2019). En este contexto, hay evidencia de propuestas constructivas para el mejoramiento en los asentamientos palafíticos (RodríguezZambran, 2014). En términos arquitectónicos se resalta la riqueza cultural que ha trascendido a lo largo de los años para la población del Pacífico colombiano, y se hace un intento por asegurar la técnica constructiva representativa 
Sociedad y Economía N 44 (Sep - dic 2021) / e-ISSN: 2389-9050 / e 10710980

María Alejandra Bermúdez-Ayala, Juan Camilo Castro-Ortiz y Johan Andrés Avendaño-Arias

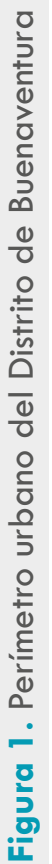
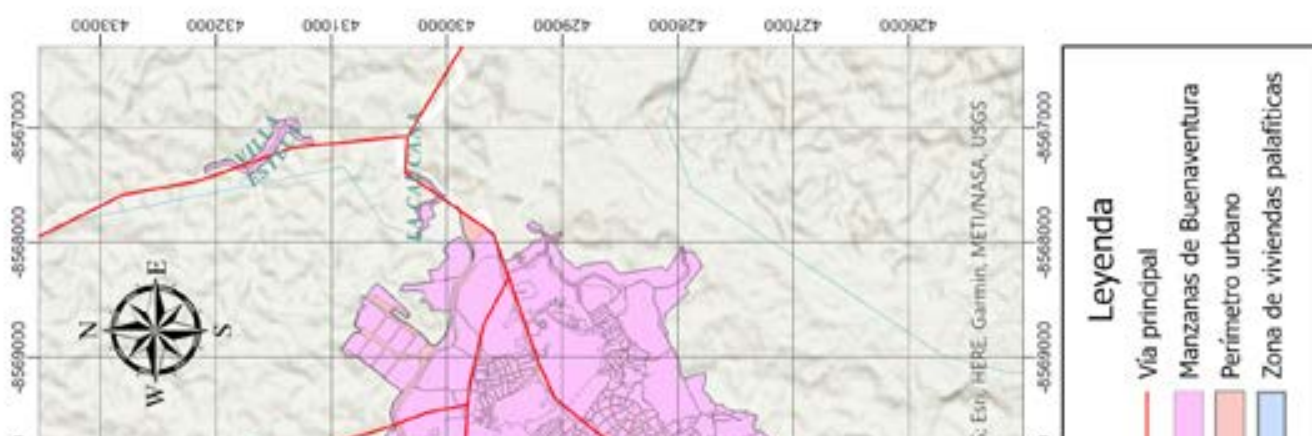

क्षे

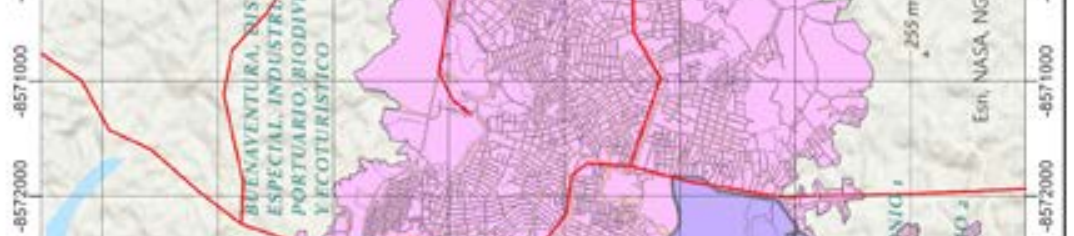

है

8
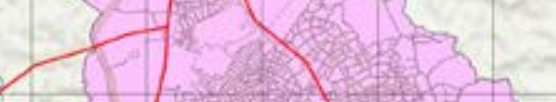
Sociedad y Economía N 44 (Sep - dic 2021) / e-ISSN: 2389-9050 / e10710980

Análisis de las técnicas valuatorias colombianas para las viviendas palafíticas del Pacífico. Caso Buena-

ventura, Valle del Cauca

en la zona, pero quizá con materiales más estables. En general, es todo un campo por revalorar.

Determinar estrategias para la preservación de las técnicas constructivas ancestrales, en procura de no permitir que continúe su deterioro y aniquilación por parte de la intromisión de la homogeneidad de la edificación urbana (Villabona, 2020), es una necesidad. Por esa razón, uno de los muchos pasos a seguir puede ser contrastar y ampliar las técnicas valuatorias, en tanto estímulo para el reconocimiento de la vivienda palafítica y su excepcionalidad, de sus valores materiales y simbólicos; en sí, todo un reto para las técnicas tradicionales de valoración en Colombia, a la hora de estimar el valor de la vivienda con matices diferenciales. Por tanto, el análisis busca una mirada integral para la valoración de viviendas palafíticas, que son la base de asentamiento para las comunidades del Pacífico colombiano. A la luz de estos planteamientos, el objetivo de este artículo es el de analizar las técnicas valuatorias colombianas, delineadas en los procedimientos de avalúos (Resolución 620 de 2008), proferida por el Instituto Geográfico Agustín Codazzi (IGAC, 2008), y su pertinencia o no para las viviendas palafíticas del Pacífico, en el occidente del país, tomando como foco el municipio de Buenaventura, Distrito del departamento del Valle del Cauca. Para esto, se indagaron las maneras constructivas, los tipos de materiales, la información accesible sobre este tipo de mercado, así como los diferentes enfoques metodológicos valuatorios, para contrastar su nivel de aplicabilidad en este tipo de bienes.

Colombia, de manera particular, ha emitido una normatividad reciente -Ley 2907 de 2021 (Congreso de la República de Colombia, 2021)en donde los palafitos -sobre los cuales tratará el siguiente texto- deberían ser reconocidos como una vivienda de interés cultural; desde ese enfoque, se aproxima la discusión del texto y se dejan unos lineamientos para que en posteriores reflexiones se pueda incluir a mayor profundidad lo planteado en la ley.

Así, el documento está constituido por 4 partes reflexivas: la primera dedicada a las pers- pectivas socioterritoriales, con el fin de ubicar las características de la región; la segunda en donde se abordan los elementos del hábitat palafítico y sus vínculos con la tradición e identidad, como base para la comprensión de la estimación de los valores de estas formas de vivienda; en tercer lugar, se profundizan los ámbitos identitarios, para dar paso a la caracterización de las estructuras constructivas predominantes. Como cuarta reflexión, se amplían todos los anteriores elementos para aplicar los diversos métodos valuatorios en los palafitos del caso de estudio (reposición a nuevo, renta, comparación del mercado y residual o potencial). Con ello se plantean entonces las convergencias y disimilitudes que poseen los métodos tradicionales al momento de valorar los precios de este tipo de viviendas.

\section{Perspectiva socio-territorial de los asentamientos en la región Pacífica de Colombia}

El territorio del Pacífico colombiano es un escenario caracterizado por tener una baja densidad poblacional y difícil acceso, sumado a que se encuentra en medio de la selva húmeda tropical ecuatorial, la cual tiene una alta humedad y una excesiva pluviosidad, configurándose en uno de los puntos con mayor biodiversidad del mundo (Osorio-Mejía, 2016). Sin embargo, las comunidades pertenecientes a la región Pacífica colombiana aparentan una situación donde "la quebrada, el paisaje, la comunidad y los asentamientos palafíticos como espacio físico, presentan condiciones que pueden considerarse de deterioro" (Palacio, 2012, p. 94). En realidad, el detrimento es generado a partir de la desatención del Estado, la deficiencia de servicios públicos y de recursos distribuidos para el mantenimiento de las estructuras de los barrios, las viviendas, los pórticos y los puentes. En términos de las estructuras palafíticas, es poco o nulo el reconocimiento como patrimonio cultural y activo competitivo territorial.

En cuanto a las características sociales del hábitat de los asentamientos palafíticos, las cifras del Censo Nacional de 2018 muestran reiteración de hacinamiento, debido a que las 
viviendas son reducidas en área y espacio, al tiempo que las estructuras familiares se caracterizan por ser numerosas y extensas. Se evidencian enlaces conyugales a temprana edad y, en su mayoría, los hombres son pescadores y las mujeres artesanas o comerciantes de pescado. Los palafitos carecen de servicios públicos como gas doméstico, por lo que es común la cocina con leña en sus fogones tradicionales. Tienen altos niveles de analfabetismo y la mayoría de los pobladores configuran grupos socioeconómicos que viven en extrema pobreza (Granell y Runge, 2007). En sí, son consideradas como viviendas en zonas de no estado, por consiguiente, zonas de No Derecho. De ahí que las entidades gubernamentales de los municipios colombianos, como por ejemplo en Sitio Nuevo, en Magdalena (también palafítico), eluden la prestación de servicios básicos para estas comunidades (López et al., 2019). Patrón que se repite en el Pacífico.

La creciente informalidad, presente en algunas viviendas palafíticas al estar ubicadas sobre superficies acuáticas, disminuye los espejos de agua por la forma de habitar poco sostenible ambientalmente. Al tiempo, el incremento poblacional que es casi exponencial, siempre buscando la cercanía a los lugares de extracción de peces en una simbiosis entre lugar de habitación, trabajo y espacio natural (López et al., 2019), ha generado que se "colonicen" cada vez más áreas, en dirección mar adentro.

Emerge también otro problema y es el de la persistencia allí de condiciones de pobreza, limitación del desarrollo de capacidades y, por ende, distancia del acceso a los sistemas laborales yeconómicos paragenerar, en el marco de sus parámetros, ascenso social (Massauh y Peyloubet, 2002). "El Estado no asume su papel social referente al mejoramiento de la calidad de vida de poblaciones afrodescendientes en situación de pobreza y desigualdad económica como si lo hace al interior del país" (RodríguezZambran, 2014, p. 26). Aun así, sus habitantes, vinculados a formas de identidad territorial y étnica, persisten en los palafitos, como una expresión de resistencia, sobreviviendo de la pesca, la recolección de ostras y cangrejos, del acompañamiento al invasivo turismo, y en ciertos casos, por la falta de oportunidad, trabajando con organizaciones criminales, dada la ubicación geográfica estratégica que posee el Pacífico para el desarrollo de economías ilegales (contrabando, narcotráfico, armas, etc.).

\section{Elementos del hábitat palafítico: tradición e identidad}

El hábitat palafítico es considerado el medio geográfico, el modo de organización y forma de asentamiento de comunidades o individuos habitando sobre cuerpos de agua, en viviendas sobre plataformas de madera u otro material, soportadas por postes de madera (Granell y Runge, 2007). La vivienda, en términos funcionales y simbólicos, se constituye en una expresión de la cultura, refleja su capacidad cognitiva y las formas como entienden $y$ clasifican el medio ambiente del Pacífico desde el siglo XVI, en remembranza incluso de los orígenes africanos de sus antecesores. En cuanto a lo palafítico, es "una estructura llamativa y vistosa; su fundamento se encuentra en una forma particular de conocer, clasificar, usar y representar la inmensa biodiversidad contenida en sus sistemas ecológicos y las complejas relaciones que se establecen entre el mundo natural y el cultural" (Garcés, 2016, p. 11).

Incluso es posible que sea considerado como una respuesta de gestión ambiental y territorial, lo cual posibilitaría una alternativa para mejorar sus condiciones de habitabilidad y saneamiento, en tanto se dignifique de manera inicial el abrigo que la estructura brinda. Sin embargo, los deterioros progresivos no permiten la valoración correcta en los asentamientos palafíticos, ni tomar en cuenta su riqueza arquitectónica y cultural a partir de la cual deberían ser reconocidos como patrimonio de los habitantes del Pacífico colombiano (Palacio, 2012), y con ello, por qué no, quizá ser ejemplo para otras regiones. Factores como la sostenibilidad y la concepción bioclimática de las viviendas son consecuencias de la prolongación de conceptos transmitidos por generaciones, con base en un conocimiento intuitivo del 
Sociedad y Economía N 44 (Sep - dic 2021) / e-ISSN: 2389-9050 / e10710980

Análisis de las técnicas valuatorias colombianas para las viviendas palafíticas del Pacífico. Caso Buena-

ventura, Valle del Cauca

medio y el clima, resultante de la experiencia (Granell y Runge, 2007). En cierta medida, es una expresión del vínculo con las tierras africanas de donde sus ancestros fueron extraídos por el imperio español, en calidad de esclavos, con destino a América. En ámbitos culturales, se describe el proceso de poblamiento del Pacífico (Aprile-Gniset, 2004; Torres y Gniset, 2006; Rosero-Labbé y Barcelos, 2009) como se observa a continuación.

\subsection{Las formaciones socioespaciales aborígenes}

Para las principales características de la formación y poblamiento en el Pacífico, aún existen evidencias arqueológicas de instrumentos utilizados en la época precolombina y de las diversas épocas que se extendieron a lo largo del Pacífico (Torres y Gniset, 2006). Se promulgó un despoblamiento y exterminio de la población nativa. Aumentó en el transcurso del siglo XVIII los enclaves mineros, por tanto, se fortaleció el trabajo forzado en las primeras minas y, como reflejo, un fortalecimiento del mecanismo de la acumulación de capital (Aprile-Gniset, 2004). Con este tránsito obligado y continuo, reflejado en huida, destierro o deportación, hoy en día son escasas las comunidades aborígenes radicadas en los sitios que fueron hábitat de sus ancestros (Osorio-Mejía, 2016) ${ }^{5}$.

\subsection{La formación socioespacial esclavista y minera}

Históricamente fue la época de conquista del Chocó, que tuvo una reducción de los pueblos nativos. Sin embargo, los alcances militares no llegaron a ser suficientes para la instalación de ciudades como lo fue en otras partes de Co-

5 Dentro de los asentamientos en la costa de la región Pacífica, es posible mencionar el grupo indígena Wounnan. Esta población es conocida popularmente como los Cholos, están ubicados en las orillas de numerosos ríos y quebradas de la cuenca media y baja del río San Juan, la cual desemboca en el océano Pacífico en el Valle del Cauca. lombia. La mina se convirtió en el centro de aglomeración, donde tanto trabajadores como capataces articulaban labores (Rosero-Labbé y Barcelos, 2009). Aún el trabajo forzado daba origen a la plusvalía de la región, con lo cual aumentaba la fortuna para la compra de esclavos (Aprile-Gniset, 2004). Las vías fluviales eran consideradas ejes integradores y de comunicación entre minas; además, el grupo de esclavos se dividió entre los de minas y los de platanares, lo que configuró el embrión del campesinado neoafricano (Torres y Gniset, 2006). Fue indispensable notar que los puertos fluviales, las rancherías (ventas y tambo), constituyeron lo esencial del amoblamiento espacial de la región del Pacífico.

\subsection{La formación socioespacial de colonización agraria}

Después de abarcar las migraciones y circulaciones humanas, se completa el desarrollo de hábitat nuevo y, por tanto, el fenómeno de población se asienta en un territorio propio. Además, un factor predominante es la colonización agraria del Pacífico, que conforma una dimensión socioterritorial con identidad propia, por las condiciones singulares de la zona. El patrón de poblamiento se acentúa en la continuidad de ríos y costas, pero con baja densidad humana. Por último, se genera una masiva promulgación de normas, con el fin de abolir el esclavismo y pasar a la servidumbre (Rosero-Labbé y Barcelos, 2009).

\subsection{Transformación a la ciudad}

Por la poca intervención del Estado, la figura de ciudad no constituye un elemento primario en la región, sino centro de acopio para los productores y agricultores, aunque se intentan adoptar las medidas de reparto predial de tipo catastral con base en la idea de propiedad individual. Para ese entonces la línea fluvial o costera de origen popular se había constituido como un patrón dominante y tradicional trazado por los pobladores. Como afirma Jacques Aprile-Gniset (2004), "la población de baja densidad regada en extensas áreas agrarias no exigía un fuerte aparato estatal urbano de administración y control" (p. 278). 
Para el año 1930, se instauraba el puerto nacional de Buenaventura, que llevó a nuevas actividades mercantiles; a la par, el despoblamiento en las selvas aumentaba y algunos migrantes llegaban a la ciudad, pero como forma de protección por la expulsión de las zonas rurales (Torres y Gniset, 2006). Lentamente, inició procesos de colonización popular urbana, entre los más grandes de la región están Quibdó, Tumaco y Buenaventura. Finalmente, para esta época los asentamientos de la región Pacífica conformaron lugares donde el suelo dio abasto solamente a una población reducida (Duarte et al., 2018). La unidad del sitio hoy en día es un problema principal, debido a la geografía alrededor de las ciudades, y hay una gran evidencia del asentamiento de poblaciones en las riberas de las vías fluviales.

Para la comprensión de los asentamientos palafíticos, se deben mencionar los vecindarios parentales, pues son considerados como la expansión de viviendas en el territorio por parte de distintos integrantes de la familia, a una distancia cercana a padres, hermanos y familiares. Dichos vecindarios están relacionados con las tipologías de herencia de viviendas, expresión muy diferente de lo que se puede encontrar hoy en otro tipo de nichos de vivienda, en donde cada vez más se pierden los espacios de socialización (Osorio-Mejía, 2016). Paralelamente, el valor patrimonial que representan los palafitos hace parte de la identidad de estos asentamientos en la región del Pacífico, inclusive se les atribuyen características patrimoniales, arquitectónicas, ecológicas y ético-sociales que afianzan los hogares en aldeas palafíticas (Figura 2).

Para algunos autores, la propuesta para la permanencia de las comunidades del Pacífico se debe concentrar en "potencializar los elementos que hacen parte de los asentamientos palafíticos, su arquitectura y expresión cultural, dando valor a los palafitos y a largo plazo desestigmatizarlos como zonas marginales y pobres" (Palacio, 2012, p. 113). En suma, es posible afirmar que los palafitos son evidencia de que la organización socioterritorial moderna en el territorio del Pacífico es producto de varias fases enlazadas de poblamiento, cada una de las cuales presenta un modo particular de organización social y productiva del espacio vital (Aprile-Gniset, 2004).

\section{Identificación de los asentamientos palafíticos en la región Pacífica de Colombia}

Dentro de los asentamientos en el litoral pacífico, García (2019) plantea algunas tipologías arquitectónicas: la primera es la arquitectura vernácula, que normalmente tiene en cuenta la reducción del calor y del asoleamiento, ubicada en zonas periurbanas y rurales; por tanto, se suelen elevar las construcciones del suelo para protegerlas de animales, del agua y también debido a que, en muchos casos, el nivel freático es muy alto y el suelo es de tipo arenoso. También se caracterizan por tener pendientes con ángulos bastantes agudos, permitiendo el fácil escurrimiento de las aguas Iluvias y dando mayor protección solar a las ventanas. Además, emplean el uso de materiales ligeros para refrescar ambientes y, en general, conservar un entorno de confort. La segunda tipología de la región, según García (2019), corresponde a la arquitectura bioclimática, la cual tiene en cuenta las condiciones del suelo, la orientación de la vivienda para captar energía y su abastecimiento, el aislamiento térmico y de materiales, los sistemas de ventilación y de enfriamiento.

Por otro lado, una de las tipologías arquitectónicas más comunes corresponde a los asentamientos palafíticos. Esta arquitectura "se separa de la tierra firme por varias razones: regulación de la temperatura, protección de posibles ataques de animales, acercamiento al medio de comunicación principal" (García, 2019 , p. 44). Estos asentamientos son un conjunto de viviendas alzadas sobre pilotes de madera, donde su construcción depende de la altura de la cota más alta de inundación del cuerpo de agua circundante (Palacio, 2012). Tienen atributos ancestrales y son usadas desde épocas precolombinas por los indígenas y negros para viviendas y en ocasiones para 
Sociedad y Economía N44 (Sep - dic 2021) / e-ISSN: 2389-9050 / e 10710980

Análisis de las técnicas valuatorias colombianas para las viviendas palafíticas del Pacífico. Caso Buena-

ventura, Valle del Cauca

Figura 2. Fotografía viviendas palafíticas en Buenaventura, Valle del Cauca

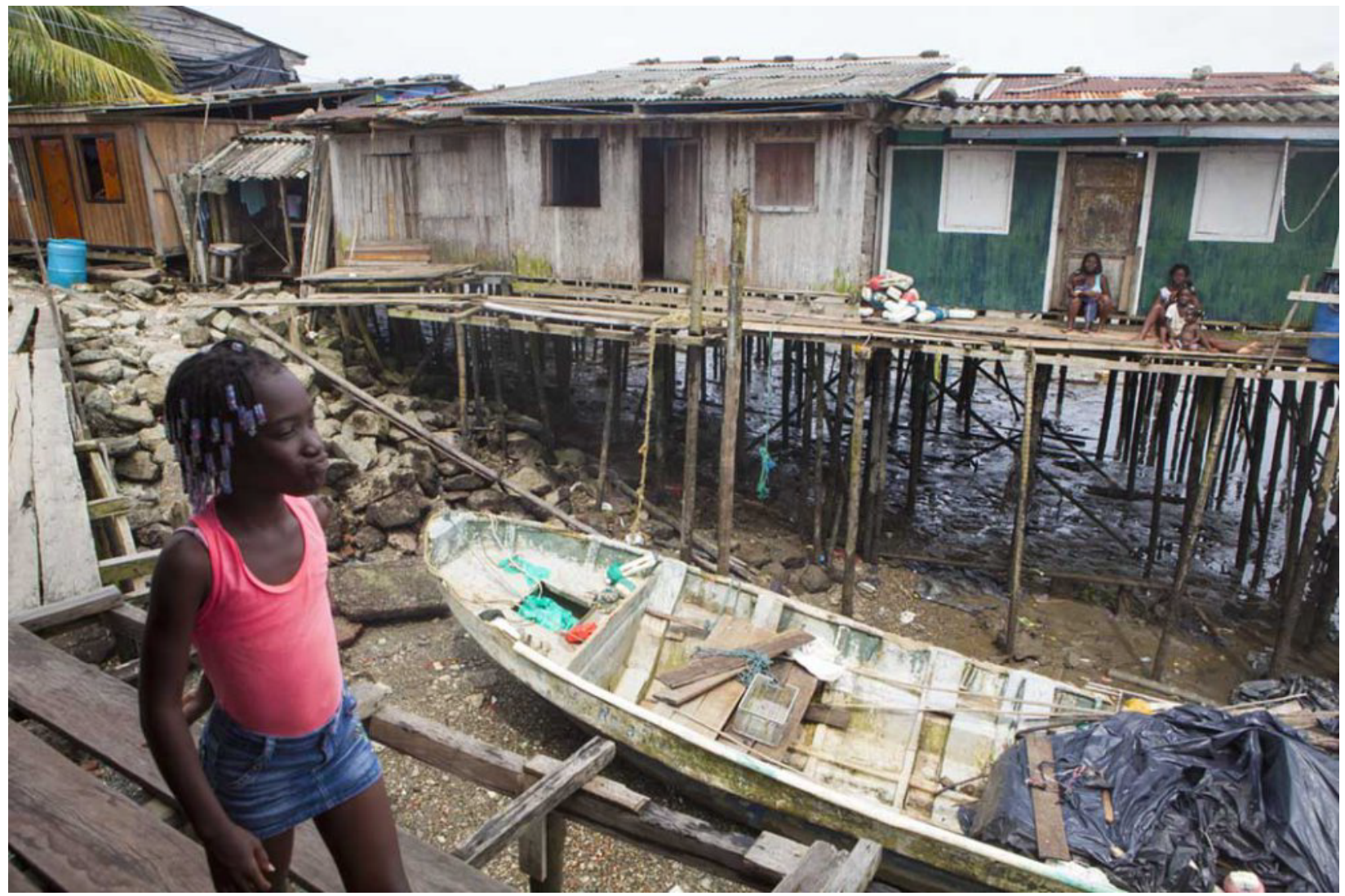

Fuente: tomado de Sulé (2016).

trabajos. Los patrones de asentamiento palafíticos generalmente se dieron de manera dispersa a orillas de los cuerpos hídricos, extendiéndose a lo largo de los ríos y quebradas (Osorio-Mejía, 2016). La unidad territorial está consagrada en un ámbito común, representado en especial por el río, que permite que los miembros de la comunidad mantengan sinergias entre sí.

La idea inicial en la construcción de viviendas palafíticas está asociada a los árboles de los bosques de costa, donde se realizaron los primeros asentamientos soportados en manglares, para sacar provecho de los vientos que allí se entrecruzan y con ello favorecer la ventilación y refrescar el asentamiento. En términos generales, iniciaron asentadas de forma dispersa a lo largo de los ríos y las costas del mar, predominando la estructura y cerramientos en madera y cubierta de zinc o palma, luego se fueron aglomerando. En comunidades establecidas, la vivienda se compone de dos palafitos, uno a cada lado de la pasarela principal que conforma el poblado (García, 2019), como si cedieran andenes o espacios públicos para el tránsito de los habitantes sobre extensos tablones. Aun cuando Palacio (2012) plantea que hay falta de procesos de organización y planificación, que se convierte en uno de los principales motivos para que estos asentamientos tengan carencias y se afecte en gran escala el medio donde se localizan, lo cierto es que los patrones de ubicación poseen su propia lógica espacial, su traza autentica, una amalgama que tiende a ser quizá algo más orgánico en sintonía con la sistémica que caracteriza el medio biofísico (Torres, 2014). Eso que para los proyectos modernos es caos, para los habitantes palafíticos es parte de su identidad, 
de su materialización de gestión ambiental y territorial.

Ahora bien, en el marco de la Ley 2079 de 2021 , además de otras leyes como la Ley 70 ya mencionada en este texto, el gobierno colombiano plantea disposiciones en materia de hábitat y vivienda. Ese documento normativo reconoce, por un lado, la necesidad de garantizar políticas públicas de vivienda en búsqueda de unas condiciones dignas y de calidad de vida para los residentes (Congreso de la República de Colombia, 2021, Art. 5, núm. 2). Asimismo, se establece la necesidad de que se incluyan políticas diferenciales en las intervenciones relacionadas con vivienda (Congreso de la República de Colombia, 2021, Art. 5, núm. 6). Por lo anterior, las reflexiones en el ámbito público deben encaminarse a reconocer que no se tiene una manera homogénea de abortar la concepción de las viviendas y sus construcciones. De hecho, la ley anteriormente mencionada ratifica la necesidad de tener un enfoque diferencial, específicamente en temas étnicos. De la misma manera, se crea la tipología de vivienda de interés cultural soportada en muchas características, algunas de ellas por tradiciones y cultura (Congreso de la República de Colombia, 2021, Art. 6), y, por ende, allí encajaría entonces una nueva manera de tipificar, de aquí en adelante, estos emplazamientos palafíticos. Teniendo en cuenta el marco de la ley mencionada, vale la pena profundizar en nuevas formas de comprensión, estudios y, por supuesto, elementos valuatorios.

\section{Estructura constructiva predominante en las viviendas palafíticas de Buenaventura}

Buenaventura es el puerto marítimo más importante de Colombia, aun cuando su grandeza portuaria y ecosistémica no es reflejada en la calidad de vida de sus habitantes, problemáticas que se expresan desde los desplazamientos forzados, pasando por la limitación de acceso a oportunidades, hasta la falta de oferta digna de servicios públicos en los ho- gares. Esta tendencia ha llevado, en otro extremo, a romantizar la morfología palafítica, pues desde las autoridades se plantea que, al ser territorios culturales, es muy difícil realizar obras de intervención, extender redes de servicios públicos y/o "mejorar" las formas materiales, pues eso, según el discurso estatal, sería intervenir la relación territorial. Así, en una mezcla incoherente de argumentos, el Estado se desliga de sus responsabilidades, convirtiéndose en cómplice de la ampliación de las brechas materiales, sociales y económicas de la población. Es una muestra de incomprensión de las relaciones de los habitantes, del uso de los materiales, de sus simbologías y del ser acreedores de derechos inalienables, como cualquier otro ciudadano, para vivir y habitar en condiciones más dignas.

La Tabla 1 describe las etapas generales de construcción de viviendas palafíticas.

\section{Alcance de los métodos valuatorios en las viviendas palafíticas de Buenaventura}

A continuación, se presentará con mayor detalle cada uno de los métodos que propone la Resolución 620 procedimiento para los avalúos proferida por el Instituto Geográfico Agustín Codazzi (IGAC, 2008) para la realización de avalúos en el territorio colombiano, con lo cual se destacan las bondades y deficiencias de la aplicación normativa valuatoria para este tipo de vivienda sostenida sobre el agua.

Para ejemplificar, a grandes rasgos, la forma valuatoria de esta tipología de vivienda se usará una construcción ubicada en el barrio San José, perteneciente a la comuna 4 de Buenaventura, exactamente sobre la Carrera 12c con Calle $1^{\text {a }}$. Como se observa en la Figura 3 , el ejercicio de valoración será realizado de forma remota a través de la herramienta Street View de Google Maps. Debemos recordar que esta zona se encuentra con poca instalación de servicios públicos, por lo cual solo hay evidencia de puntos de tomacorriente para cada vivienda, los servicios de alcantarillado y acueducto aún no son instalados en la zona, además 
Sociedad y Economía N44 (Sep - dic 2021) / e-ISSN: 2389-9050 / e 10710980

Análisis de las técnicas valuatorias colombianas para las viviendas palafíticas del Pacífico. Caso Buena-

ventura, Valle del Cauca

Tabla 1. Etapas generales de fabricación de vivienda palafítica

\begin{tabular}{cl} 
Etapa & Descripción Acción \\
\hline 1 & $\begin{array}{l}\text { Selección de las maderas para la construcción y ubicación de la vivienda, definición de la altura del } \\
\text { palafito, limpieza y adecuación del sitio, fijación de los pilotes, horcones de madera resistentes a la } \\
\text { humedad. }\end{array}$ \\
2 & $\begin{array}{l}\text { Inicio de la ubicación y puesta de parales para las paredes y soportes de la cubierta. } \\
3\end{array}$ \\
4 & Fabricación del piso elevado, entramado de "madres durmientes". \\
5 & Elaboración de paredes con tablas aserradas, dispuesta de forma horizontal o vertical. \\
6 & Terminación y puesta de puertas y ventanas, detalles finales de ornamentación.
\end{tabular}

Fuente: tomado de Garcés (2016).

Figura 3. Fotografía vivienda palafítica en la comuna 4 de Buenaventura, Valle del Cauca

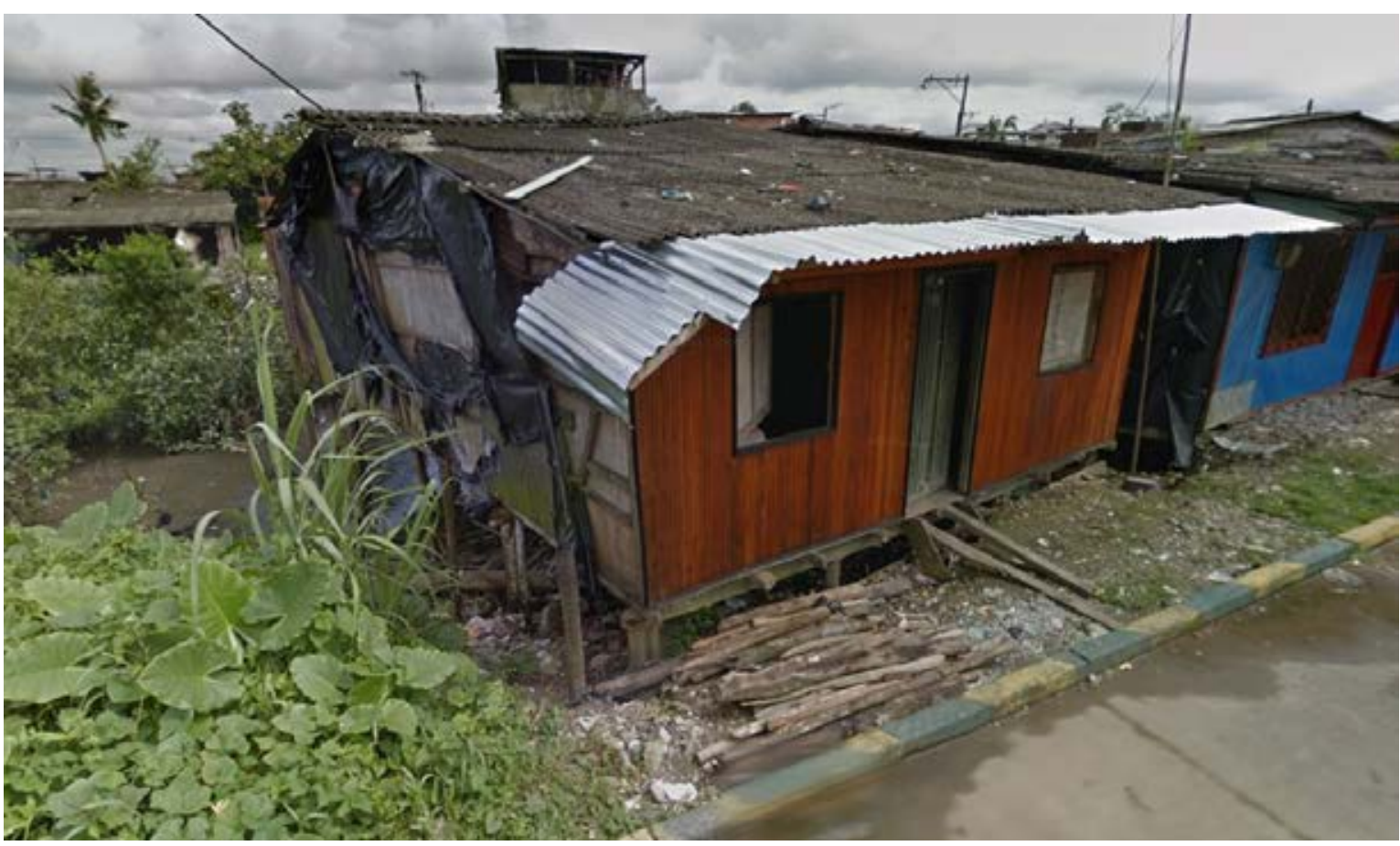

Fuente: tomado de Street View en Google Maps (2013).

se evidencian vías secundarias pavimentadas, pero espacios públicos, como andenes, sin ninguna mejora en el sector.

Las viviendas palafíticas están esencialmente constituidas por materiales vegetales presentes en su entorno, la múltiple biodiversidad de esta región garantiza la accesibilidad a los distintos tipos de árboles. El interior de estas viviendas, según lo describe Gilma Torres (2014) en su libro Vivienda y arquitectura tradicional en el pacífico colombiano, patrimonio cultural afrodescendiente, son generalmente distribuidas en circulación lateral o central, cuentan con 2 o 3 habitaciones ubicadas en el centro de la vivienda, una sala y cocina, y una zona de servicios que da sobre el mar. La construcción es realizada comúnmente de forma autónoma y con conocimientos de herencia tradicional de las comunidades. Es así como la expansión de esta tipología de vivienda se da por medio de vecindarios parentales, como se mencionó anteriormente. 


\subsection{Método Costos de Reposición}

La vivienda palafítica, al ser una tipología excepcional de vivienda, hace referencia a un tipo de hábitat no común y con distintas fases constructivas, su valorización económica conlleva a muchos inconvenientes en establecer un método correcto y preciso para ser implementado. Uno de los principales problemas valuatorios presente en estas viviendas es la no estabilización de la construcción en un predio, sino, por el contrario, su ubicación en los litorales acuáticos de la región. Por ello, su valor más relevante sería los materiales, tiempo, y trabajo realizado para el levantamiento de estas construcciones. El proceso valuatorio acorde a esta situación es el Método de Costo de Reposición, descrito brevemente en la Resolución procedimiento para los avalúos (Resolución 620 de 2008), como un método encargado de establecer el valor comercial de un bien a partir de la estimación del costo total de la construcción, a precio de hoy, restándole la depresión generada por su tiempo de uso (IGAC, 2008).

Es de vital importancia el conocimiento de las fases constructivas de estas viviendas en la región del Pacífico, debido a la implementación de distintos tipos de madera, usados comúnmente en la arquitectura constructiva de las viviendas. El uso adecuado de las propiedades biofísicas y bioquímicas de la vegetación presente en estos sectores es de gran relevancia en aspectos como la estabilidad, soporte, resistencia al agua y diseño tradicional de la vivienda. En la estimación de los valores que representan estos materiales se debe tener en cuenta la accesibilidad a estos mismos por parte de la comunidad, ya que es la encargada de la construcción de sus viviendas. Otro factor relevante para establecerse en la estimación del valor de estas construcciones, por este método, será la inexistencia, en la mayoría de los sectores de Buenaventura, de servicios públicos básicos en sus viviendas, o en condiciones precarias.

En el caso puntual de la vivienda tradicional en cuestión, se establecieron 4 fases constructivas esenciales. La primera instancia, y una de las más importantes, es la implantación de los pilares de madera, debido a que esta etapa involucra la característica primordial de las viviendas pala- fíticas, y cuyo propósito principal es darle soporte, estabilidad y protección a la vivienda de posibles subidas del nivel medio del mar, evitando así inundaciones. Como se observa en la Figura 3 , se logra detectar que estos son pilares a base de madera de mangle. Este tipo de madera es comúnmente usada por su resistencia al agua y por contener gran cantidad de fibra para brindar un soporte ideal.

La siguiente etapa es la construcción de la estructura base de la vivienda. En esta fase, se establece la colocación de parales, plataforma (esta va ligada a la construcción de los bloques "madre" como primer soporte de la plataforma), paredes y pisos (si esta lo requiere). Es importante resaltar que este tipo de vivienda se desarrolla comúnmente en Buenaventura a base de madera como el nato, aceite de maría, quinde, o maderas que generen flexibilidad, impermeabilidad y le den soporte a la vivienda. En el texto expuesto por Carlos Ordóñez y José Orozco (2019), Tipificación y Análisis de Precios Unitarios para la vivienda campesina en el departamento de Putumayo, se resalta una vivienda en la vereda $\mathrm{La}$ Castellana, la cual es netamente construida a base de madera y cuyo valor expuesto por los autores podría brindar claridad a un valor aproximado de la vivienda en cuestión. Es importante destacar que, al ser un ejercicio de valorización de forma remota, no se cuenta con mediciones del terreno ni de construcción de la vivienda. Teniendo en cuenta lo anterior, se establecieron medidas hipotéticas para determinar un valor aproximado. En la Tabla 2, se especifican estos valores.

En la etapa de la construcción de la cubierta se debe resaltar que este tipo de vivienda no cuenta con cielo raso por su diseño tradicional, comúnmente se usa madera de palo mulato para realizar la estructura de la cubierta y se usa teja de fibrocemento o zinc. Como última fase constructiva, se presentan las terminaciones y ornamentaciones finales, correspondientes a la instalación de ventanas y puertas de la vivienda. En la Figura 3, se observa que estas terminaciones son a base de madera. Cabe aclarar que la determinación de las medidas para realizar una valorización de estas últimas 2 fases es igualmente hipotética y su valor podría variar. 
Sociedad y Economía N 44 (Sep - dic 2021) / e-ISSN: 2389-9050 / e 10710980 Análisis de las técnicas valuatorias colombianas para las viviendas palafíticas del Pacífico. Caso Buena-

ventura, Valle del Cauca

Tabla 2. Presupuesto de vivienda palafítica en estudio, Barrio San José, Comuna 4 de Buenaventura

\begin{tabular}{|c|c|c|c|c|c|c|c|}
\hline Ítem & Descripción & Unid. & Cant. & $\begin{array}{l}\text { V. Unid. } \\
\text { Pesos COP }\end{array}$ & $\begin{array}{l}\text { V. Parcial } \\
\text { Pesos COP }\end{array}$ & $\begin{array}{l}\text { V. Unid. } \\
\text { Dólar USD }\end{array}$ & $\begin{array}{l}\text { V. Parcial } \\
\text { Dólar USD }\end{array}$ \\
\hline 1 & Estructura & & & & $\$ 7 ' 158.156,3$ & & $\$ 1.863,04$ \\
\hline 1.1 & $\begin{array}{c}\text { Suministro e insta- } \\
\text { lación de columna } \\
\text { en madera (pilote) } \\
0,2 \times 0,22 \times 1,0 \mathrm{~m}\end{array}$ & $M L$ & 48 & $\$ 51.387$ & $\$ 2 ' 466.581,42$ & $\$ 13,37$ & $\$ 641,97$ \\
\hline 1.2 & $\begin{array}{l}\text { Suministro e ins- } \\
\text { talación de co- } \\
\text { lumna en madera } \\
0,2 \times 0,2 \times 1,0 \mathrm{~m}\end{array}$ & $M L$ & 48 & $\$ 48.423,4$ & $\$ 2 ' 315.683,25$ & $\$ 12,56$ & $\$ 602,7$ \\
\hline 1.3 & $\begin{array}{l}\text { Suministro e } \\
\text { instalación de } \\
\text { viga en madera } \\
0,2 \times 0,2 \times 1,0 \mathrm{~m}\end{array}$ & $M L$ & 48 & $\$ 49.497,74$ & $\$ 2 ’ 375.891,62$ & $\$ 12,88$ & $\$ 618,37$ \\
\hline 2 & Cubierta & & & & \$ 1'161.064,14 & & $\$ 302,19$ \\
\hline 2.1 & $\begin{array}{c}\text { Cubierta en lámina } \\
\text { de Zinc }\end{array}$ & M2 & 24 & $\$ 27.563,02$ & $\$ 661.512,41$ & $\$ 7,17$ & $\$ 172,17$ \\
\hline 2.2 & $\begin{array}{l}\text { Suministro e insta- } \\
\text { lación de viga en } \\
\text { madera } 0,1 \times 0,15 \\
\times 1,0 \mathrm{~m}\end{array}$ & $M L$ & 10,4 & $\$ 48.033,82$ & $\$ 499.551,73$ & $\$ 12,5$ & $\$ 130,02$ \\
\hline 3 & Terminaciones & & & & $\$ 325.786$ & & $\$ 84,79$ \\
\hline 3.1 & $\begin{array}{l}\text { Suministro e insta- } \\
\text { lación de puerta } \\
\text { en madera } 1,9 \times 0,8 \\
\mathrm{~m}\end{array}$ & UN & 1 & $\$ 171.469,57$ & $\$ 171.469,57$ & $\$ 44,63$ & $\$ 44,63$ \\
\hline 3.2 & $\begin{array}{c}\text { Suministro e insta- } \\
\text { lación de ventana } \\
\text { en madera } 1,9 \times 0,8 \\
\mathrm{~m}\end{array}$ & UN & 2 & $\$ 77.158,21$ & $\$ 154.316,42$ & $\$ 20,08$ & $\$ 40,16$ \\
\hline 4 & $\begin{array}{c}\text { Instalaciones } \\
\text { eléctricas }\end{array}$ & & & & $\$ 1 ' 005.616,81$ & & $\$ 261,73$ \\
\hline 4.1 & $\begin{array}{c}\text { Salida interruptor } \\
\text { doble }\end{array}$ & UN & 1 & $\$ 64.370,64$ & $\$ 64.370,64$ & $\$ 16,75$ & $\$ 16,75$ \\
\hline 4.2 & $\begin{array}{l}\text { Salida interruptor } \\
\text { sencillo }\end{array}$ & UN & 3 & $\$ 54.491$ & $\$ 163.473,01$ & $\$ 14,18$ & $\$ 42,55$ \\
\hline 4.3 & $\begin{array}{l}\text { Salida tomaco- } \\
\text { rriente } 110 \mathrm{~V}\end{array}$ & UN & 3 & $\$ 56.249,39$ & $\$ 168.748,16$ & $\$ 14,64$ & $\$ 43,92$ \\
\hline 4.4 & $\begin{array}{c}\text { Bombillo aplique } \\
\text { de } 100 \mathrm{~W}\end{array}$ & UN & 3 & $\$ 45.822,74$ & $\$ 137.468,23$ & $\$ 11,93$ & $\$ 35,78$ \\
\hline 4.5 & $\begin{array}{l}\text { Suministro e insta- } \\
\text { lación (acometida, } \\
\text { contador, caja, } \\
\text { distribuidor) }\end{array}$ & GL & 1 & $\$ 471.556,77$ & $\$ 471.566,77$ & $\$ 122,73$ & $\$ 122,73$ \\
\hline & Costo total & & & & $\$ 9 ' 650.623,25$ & & $\$ 2.511,74$ \\
\hline & $\begin{array}{l}\text { Valor metro } \\
\text { cuadrado }\end{array}$ & & & & $\$ 402.109,3$ & & $\$ 104,66$ \\
\hline
\end{tabular}

Nota: los precios dados están en dólares y pesos colombianos (año 2021).

Precio de dólar tasa de cambio: \$3.842,2 COP (tomado el 15 de agosto 2021). 


\subsection{Método de Rentas}

Una vez estimado el valor del predio, a partir del estudio de la estructura constructiva, es posible profundizar en otra forma de estimación para el valor de la vivienda tradicional en cuestión, a partir del análisis de los ingresos generados debido a la ubicación del predio y sus condiciones geográficas. Aunque la vivienda palafítica sea considerada una forma tradicional residencial, existe una connotación favorable debido a la cercanía al cuerpo de agua, lo cual posibilita actividades de pesca y acuicultura, que permiten un ingreso para la subsistencia de los habitantes de la vivienda.

Lo anterior se asimila con el método expresado en la normativa de valuación colombiana, Resolución procedimiento para los avalúos (Resolución 620 de 2008), la cual define el Método de Rentas como la técnica que trata de establecer el valor comercial de un bien de acuerdo con las rentas o ingresos obtenidos, que son comparables por sus características físicas, de uso y ubicación (IGAC, 2008). Es así como, desde hace varios años, el ingreso generado a partir de la ubicación en zonas pesqueras posibilita la asignación del valor predial a las viviendas de tipología palafítica, pues a medida que las estructuras habitacionales sean consideradas con alguna valoración, gracias a las actividades económicas que puedan establecerse allí, el mejoramiento a dichas construcciones y el fomento de estructuras resistentes pueden hacer que la comunidad habite en unidades seguras y que trasciendan las actividades económicas y culturales para los habitantes de Buenaventura.

A pesar de que hay proximidad con la zona de trabajo, existe un desafío para los residentes de la vivienda porque deben matricular la embarcación a utilizar y mejorar la seguridad en las labores de pesca (Esquivel et al., 2016). Además, para la estimación del valor de la vivienda es necesario un registro con mayor detalle de las toneladas extraídas por la pesca artesanal y cómo influye la cercanía de la vivienda a los centros de trabajo. Esta información se encuentra a nivel general en todo el municipio de Buenaventura por las estadísticas de desembarco y esfuerzo de las pesquerías artesanales e industriales de Colombia del Ser- vicio Estadístico Pesquero Colombiano SEPEC, el cual es la herramienta principal de la Autoridad Nacional de Acuicultura y Pesca AUNAP (FAO/MADR, 2015). De acuerdo con las causas expuestas no es posible asignar un valor puntual a la vivienda en estudio; sin embargo, es posible que con información más precisa y detallada se consolide una estimación del valor predial del palafito en valoración.

Un concepto relevante para este método es el derecho a la propiedad colectiva. Este término es directamente concertado en las comunidades negras del Pacífico colombiano y, como lo describe la Ley 70 de 1993 (Congreso de la República de Colombia, 1993), la ocupación colectiva es representada por asentamientos históricos y ancestrales, donde las comunidades de esta índole utilizan tierras de uso colectivo; allí constituyen su hábitat y desarrollan las prácticas tradicionales de producción.

Es indispensable entender que sobre el análisis de transacciones de terrenos en los casos de los resguardos o de comunidades étnicas, la tendencia es la de transferir la "propiedad" de una porción de tierra en procesos de herencia. Esto no quiere decir que no exista un tipo de mercado inmobiliario, no. Es posible que haya transferencia de dominio por medio de transacciones económicas o en especie, de palabra principalmente, pero que no son legalmente reconocidas, aun cuando sí lo son en las relaciones del conjunto social. En realidad, es la expresión de la modalidad de usufructo y posesión y, por tanto, no se transfería la propiedad de la tierra, sino el derecho a su provecho o goce (Edda, 2010). De esa forma, el espacio comunal, normalmente de naturaleza corporativa, fue cediéndole terreno al individualizado, con la consecuente fragilidad de usos, costumbres y valores ancestrales.

\subsection{Método de Comparación de Mercados}

En cuanto a los dos métodos adicionales descritos en la resolución, se debe entender que no posibilitan la asignación del valor comercial a la vivienda palafítica, debido a que los demás métodos no tienen en cuenta la estructura 
Sociedad y Economía N 44 (Sep - dic 2021) / e-ISSN: 2389-9050 / e10710980

Análisis de las técnicas valuatorias colombianas para las viviendas palafíticas del Pacífico. Caso Buena-

ventura, Valle del Cauca

constructiva ni la representación cultural que lleva consigo dicha vivienda. En el caso del Método de Comparación de Mercados, definido en la Resolución procedimiento para los avalúos (Resolución 620 de 2008) como la técnica que establece el valor comercial a partir de las ofertas de bienes semejantes y comparables al predio objeto de avalúo (IGAC, 2008), para esta situación en particular, sin la existencia de ofertas y la no consideración de viviendas palafíticas de uso completamente legal, queda corta la estimación del valor hasta que se realice un avalúo que abarque las condiciones constructivas de este tipo de vivienda tradicional y resalte el valor cultural que presentan los palafitos.

Para la vivienda en estudio, este método afronta un gran reto por la condición del mercado inmobiliario que presenta la comuna 4 de Buenaventura, en donde varios predios asumen la condición de asentamientos informales; por tanto, la disposición de ofertas prediales queda corta para lograr estimar correctamente el valor de la vivienda palafítica. Con este método se demuestra la importancia de contar con información catastral actualizada, para otorgar un valor económico a viviendas étnicas y tradicionales. Aun cuando sus dinámicas no se plieguen a los pasos y los marcos de la Resolución valuatoria de Colombia, esto no quiere decir que en zonas de palafitos no existan formas de mercados inmobiliarios. No es cierto, pues de hecho sí hay transacciones de palafitos, que utilizan la comparación entre el mismo universo, para estimar los valores por los que serían "vendidos" o transados.

\subsection{Método Residual o Potencial}

Por otro lado, para el Método Residual, definido en la Resolución procedimiento para los avalúos (Resolución 620 de 2008) como la técnica que busca establecer el valor comercial del bien, normalmente para el terreno, a partir de estimar el monto total de las ventas de un proyecto de construcción (IGAC, 2008), la valoración predial sigue siendo un reto para este tipo de vivienda tradicional, debido a que desde el Pacto Colectivo realizado para el municipio de Buenaventura (Concejo Municipal de Buenaventura, 1999) y la adopción de la normativa POT de Buenaventura (Concejo Municipal de Buenaventura, 2001) hasta el actual instrumento de planificación territorial (Concejo Municipal de Buenaventura, 2013), se establece que la zona donde se encuentra el asentamiento palafítico en estudio está en riesgo mitigable, por su ubicación a mar abierto, y aunque en las actualizaciones de la normativa territorial de Buenaventura se propone la reubicación, aún no se llega a un consenso con la comunidad para el mejoramiento de las condiciones del hábitat y la conservación de la tradición cultural de las viviendas sobre estos territorios. Hasta el día de hoy, existe un considerable grupo de familias que persiste en el asentamiento palafítico y la normativa territorial requiere de un gran desafío de concertación con la población de Buenaventura.

En el caso puntual, la vivienda se encuentra localizada en un espacio geográfico que no posibilita futuros desarrollos urbanísticos que permitan estimar su valor económico puntual potencial. En adición, la vivienda palafítica no cuenta con una estructura constructiva sostenible que proteja a los residentes; de hecho, el Departamento Nacional de Planeación (DNP, 2016) afirma que son viviendas vulnerables ante eventos climatológicos. Sumado a lo anterior, son viviendas vulnerables a la contaminación del medio ambiente (Montaño, 2019) por la inadecuada disposición de desechos. Lo que desencadena en el aumento en la incidencia de enfermedades hídricas, gastrointestinales, dermatológicas y otras relacionadas (DNP, 2016). Finalmente, la vivienda palafítica en Buenaventura representa una estrategia de apropiación y transformación del espacio para atender las exigencias de sus pobladores, pero las condiciones de salubridad brindadas no son óptimas.

\section{Consideraciones finales}

La vivienda palafítica es vista por sus habitantes como una alternativa para mejorar el funcionamiento económico que se presenta en sectores como Buenaventura, tal como lo han hecho por décadas, al sacar provecho de los 
frutos del mar al que tienen acceso desde las puertas de sus viviendas. Aun así, el desplazamiento forzado poblacional genera que estas zonas sean los hábitats que reciben ya no solo a población afro, sino a habitantes que no tienen la posibilidad de acceder al resto del mercado inmobiliario del centro urbano. Situación que profundiza las tensiones, pues ya hay un acumulado de ausencias sociales, que se hacen inmanejables en la medida en que incrementa la demanda, en contraste con una baja oferta estatal. En suma, al no plantearse maneras integrales de acercarse a las poblaciones de la cultura palafítica, el único resultado que se está logrando es el del incremento de la insalubridad, la pobreza y la marginalidad.

Se han generado varios proyectos arquitectónicos que buscan el mejoramiento de estas construcciones, sin perjudicar todo su diseño autóctono y tradicional, generando una mejora en la calidad de vida de los habitantes. Esta posibilidad debe ir arraigada con un reconocimiento valuatorio existente de las viviendas. Es indispensable no solo establecer un valor de estas viviendas vernáculas por parte de los materiales, tiempo, trabajo realizado y rentabilidad que puedan tener, sino que, como se ha mencionado con anterioridad, esta tipología de vivienda requiere un reconocimiento innato de la flora presente en su marco más próximo. Todo esto implica un proceso de recolección de conocimiento heredado de generación en generación, haciendo que no solo sea visto como un tipo de construcción normal, sino como una vivienda tradicional de la comunidad negra e indígena. Es decir, de posicionar esta construcción social, incluso como una manera de gestión ambiental y territorial.

De la misma manera, tal como ya se planteó en el texto en el marco de la Ley 2079 de 2021 , al reconocerse la existencia de vivienda de interés cultural en Colombia, y al considerarse que los asentamientos palafíticos tienen cabida en ello (Congreso de la República de Colombia, 2021), se incita a seguir generando reflexiones de las tipologías de abordaje de manera diferencial para estas características constructivas, en donde se revele la carga de tradición y todo lo que hace únicas y excepcionales a las estructuras palafíticas.
La importancia de la aplicación de técnicas valuatorias sobre las viviendas palafíticas en Buenaventura radica en la asignación de valor para los predios comunes de los barrios populares de la ciudad portuaria, los cuales, además de contar con una extensa tradición constructiva y cultural, sirven de sustento económico, por su cercanía a la fuente de ingresos de la mayoría de habitantes de la zona. Por lo cual se requiere una evaluación de las viviendas según su estructura constructiva, además de la figura simbólica para los pobladores.

A medida que la estimación de valor para dichas viviendas se generalice en todos los asentamientos palafíticos, mayor será la consideración tanto de habitantes como de entidades locales para la promoción de viviendas dignas y seguras. Se presenta un desafío para que las técnicas valuatorias colombianas contemplen tipologías tradicionales de vivienda sobre el agua, lo cual puede posibilitar recursos económicos para invertir en vivienda o mejorar sus condiciones de acuerdo con los estándares de construcción, así como acceder a materiales adecuados para la edificación y, finalmente, disponer completamente de servicios domiciliarios básicos (agua, electricidad y drenaje), que mejoren la calidad de vida de las personas. Las viviendas palafíticas representan una tipología constructiva representativa de la región Pacífica colombiana; por tanto, dentro de los métodos valuatorios se debe dar respuesta a la valoración de dichas unidades, a través de la adaptación de técnicas y procesos que reconozcan el valor arquitectónico de los palafitos de Buenaventura.

En suma, si bien el método que más se acerca a la estimación de los valores es de costos de reposición a nuevo, esto no implica que los demás métodos no deban pensarse como aproximaciones para resolver este tipo de retos, que se salen de los parámetros de los bienes inmuebles urbanos. Algunos pueden considerar que los palafitos son simples mejoras, sin lote ni territorio, casi sin condiciones de propiedad o dominio, pero las dinámicas sociales de base mues- 
Sociedad y Economía N 44 (Sep - dic 2021) / e-ISSN: 2389-9050 / e10710980

Análisis de las técnicas valuatorias colombianas para las viviendas palafíticas del Pacífico. Caso Buena-

ventura, Valle del Cauca

tran que sí son formas de hábitat que no pueden estimarse únicamente por sus endebles materiales, pues por el contrario han configurado lógicas de mercado entre ellas (algo alejadas de las reglas tradicionales de las teorías de la renta). Es decir, cuando media un gran peso de significado identitario e histórico, no basta con calcular cuánto valen las maderas o mano de obra: al ser referentes de pertenencia, imponen retos de categorización.

\section{Referencias}

Aprile-Gniset, J. (2004). Apuntes sobre el proceso de poblamiento del Pacífico. En M. Pardo, C. Mosquera y M. Ramírez (Eds.), Panorámica afrocolombiana: Estudios sociales en el Pacífico (pp. 269-290). Instituto colombiano de Antropología e Historia -ICANH-; Universidad Nacional de Colombia.

Ávila, S. E. y Toro, J. C. (2003). Entre lo vernáculo y lo contemporáneo reinterpretación de la vivienda palafítica en Buenaventura (tesis de doctorado). Universidad Nacional de Colombia, Bogotá, Colombia. https://repositorio.unal.edu.co/handle/unal/3175?locale-attribute=pt_BR

Concejo Municipal de Buenaventura. (1999, 15 de octubre). Pacto colectivo por el municipio de Buenaventura. http://www.archivodelosddhh.gov.co/saia_release1/almacenamiento/APROBADO/2017-09-04/310180/ anexos/1_1504552668.pdf

Concejo Municipal de Buenaventura. (2001). Acuerdo No. 03. Por medio del cual se adopta el Plan de Ordenamiento Territorial para el municipio de Buenaventura. https://www.buenaventura.gov.co/images/ multimedia/acuerdo_pot.pdf

Concejo Municipal de Buenaventura. (2013). Plan de Ordenamiento Territorial de Buenaventura "Convivencia Pacífica desde la Diversidad". https://repositoriocdim.esap.edu.co/bitstream/ handle/123456789/9518/1813-7.pdf?sequence=7\&isAllowed $=y$

Congreso de la República de Colombia. (1993, 27 de agosto). Ley 70. Por la cual se desarrolla el artículo transitorio 55 de la Constitución Política. DO. 41013. http://www.suin-juriscol.gov.co/viewDocument. asp?ruta=Leyes $/ 1620332$

Congreso de la República de Colombia. (2021, 14 de enero). Ley 2079. Por medio de la cual se dictan disposiciones en materia de vivienda y hábitat. DO. 51557. http://www.suin-juriscol.gov.co/ viewDocument.asp?ruta=Leyes/30040331

DANE -Departamento Administrativo Nacional de Estadística-. (2018). Descarga MGN integrado a la información del CNPV - Archivos Disponibles. https://geoportal.dane.gov.co/servicios/descarga-ymetadatos/visor-descarga-geovisores/

DNP -Departamento Nacional de Planeación-. (2016). Construcción viviendas palafíticas (pendiente aval sectorial). Gobierno de Colombia.

Duarte, C., Baltán, C., Castaño, A., Espinosa, A., Vélez, D. A. G., Guerrero, A., Ledesma, J., Montaño, M., Talero, J. A. N., Solarte, A. M. y Valencia, L. E. (2018). Transformaciones y necesidades contemporáneas de las territorialidades rurales afrocolombianas: Entables, baldíos y haciendas: Ios casos del Chocó, Urabá, oeste antioqueño, Pacífico sur y valles interandinos. Pontificia Universidad Javeriana-Cali.

Edda, O. S. (2010). Valoración, partición y distribución de la tierra de los resguardos indígenas en una localidad andina venezolana. Santa Bárbara de Chachopo. Anuario de Estudios Americanos, 67(2), 679709. https://doi.org/10.3989/aeamer.2010.v67.i2.524

Esquivel, M. A., Merino, M. C., Restrepo, J. J., Narváez, A., Polo, C., Plata, J. y Puentes, V. (2016). La pesca y la Acuicultura en Colombia. OCDE. 
FAO/MADR -Organización de las Naciones Unidas para la Alimentación y la Agricultura / Ministerio de Agricultura y Desarrollo Rural-. (2015). Política Integral para el Desarrollo de la Pesca Sostenible en Colombia. FAO; MADR.

Gallego, B. E. y Selvaraj, J. J. (2019). Evaluation of coastal vulnerability for the District of Buenaventura, Colombia: A geospatial approach. Remote Sensing Applications: Society and Environment, 16, 100263. https://doi.org/10.1016/j.rsase.2019.100263

Garcés, E. C. (2016). La vivienda palafítica del Pacífico: Expresión y persistencia de una forma de ver el mundo. Biblioteca Virtual Miguel de Cervantes. http://www.cervantesvirtual.com/obra/la-viviendapalafitica-del-pacifico-expresion-y-persistencia-de-una-forma-de-ver-el-mundo-872862/

García, X. J. (2019). Propuesta de diseño arquitectónico de viviendas flotantes en riberas de ríos del litoral ecuatoriano (tesis de pregrado). Universidad Laica Vicente Rocafuerte, Guayaquil, Ecuador. http:// repositorio.ulvr.edu.ec/handle/44000/3049

Google Maps. (2013). Street View, Buenaventura, Colombia. https://www.google.com/maps/@3.8797379,77.0710316,3a,37.5y,157.82h,82.21 t/data=!3m6!1 e1!3m4!1 ss79oXcTiqDX5X9wzFvUgaA!2e0!7i13312!8i6656

Granell, F. M. y Runge, C. G. (2007). El palafito como hábitat milenario persistente y reproducible: Modelos palafíticos en el Lago de Maracaibo. En A. Aranda, F. Ollero, F. Quiles y R. Rodríguez-Varo (Eds.), Arquitectura vernácula en el mundo ibérico: actas del congreso internacional sobre arquitectura vernácula (pp. 208217). Universidad Pablo de Olavide.

IGAC -Instituto Geográfico Agustín Codazzi-. (2008, 23 de septiembre). Resolución 620 de 2008. Por la cual se establecen los procedimientos para los avalúos ordenados dentro del marco de la Ley 388 de 1997. DO. 47124. https://www.alcaldiabogota.gov.co/sisjur/normas/Norma1.jsp?i=36158

IGAC -Instituto Geográfico Agustín Codazzi-. (2021). Datos abiertos Subdirección de Catastro del IGAC. https://geoportal.igac.gov.co/contenido/datos-abiertos-catastro

López, C., Medina-Garzón, H. y Arteaga-Botero, G. A. (2019, junio). Análisis de patrones morfológicos en conjunto de vivienda palafítica: Vivienda vernácula en el corregimiento del Morro (Nueva Venecia), municipio de Sitionuevo, Magdalena-Colombia (ponencia). XI Seminario Internacional de Investigación en Urbanismo, Barcelona, España - Santiago, Chile. https://doi.org/10.5821/siiu.6484

Massauh, H. y Peyloubet, P. (2002). Desarrollo tecnológico en el marco de un proyecto de investigación y transferencia en el hábitat popular. Tecnología y Construcción, 18(1), 9-18. http://saber.ucv.ve/ojs/ index.php/rev_tc/article/view/3442

Montaño, N. A. (2019). Diagnóstico de los principales problemas ambientales en los territorios ganados al mar en el área urbana el distrito de Buenaventura. Sabia Revista Científica, 5(1), 159-171. https://doi. org/10.47366/sabia.v5n1al1

Ordóñez, C. N. y Orozco, J. A. (2019). Tipificación y análisis de precios unitarios para la vivienda campesina en el departamento del Putumayo (trabajo de especialización). Universidad Distrital Francisco José de Caldas, Bogotá, Colombia. http://repository.udistrital.edu.co/handle/11349/14514

Osorio-Mejía, N. (2016). Vivienda tradicional para el resguardo Wounaan Unión Balsalito, Chocó (tesis de pregrado). Pontificia Universidad Javeriana, Bogotá, Colombia. http://repository.javeriana.edu.co/ handle/10554/20205

Palacio, A. (2012). Gestión ambiental en la planificación de asentamientos palafíticos: Estudio de caso barrio Chambacú en la ciudad de Quibdó (tesis de maestría). Pontificia Universidad Javeriana, Bogotá, Colombia. http://repository.javeriana.edu.co/handle/10554/15639

Rodríguez-Zambran, F. E. (2014). Formulación de lineamientos básicos para el planeamiento de los asentamientos palafíticos en las zonas de baja mar de Tumaco - Nariño (tesis de maestría). Pontificia Universidad Javeriana, Bogotá, Colombia. http://repository.javeriana.edu.co/handle/10554/15558 
Sociedad y Economía N44 (Sep - dic 2021) / e-ISSN: 2389-9050 / e 10710980

Análisis de las técnicas valuatorias colombianas para las viviendas palafíticas del Pacífico. Caso Buena-

ventura, Valle del Cauca

Rosero-Labbé, C. y Barcelos, L. (Eds.). (2009). Afro-reparaciones: Memorias de la esclavitud y justicia reparativa para negros, afrocolombianos y raizales. Universidad Nacional de Colombia.

Servigna, A. (2007). Un palafito Añún: pieza del patrimonio venezolano. En A. Aranda, F. Ollero, F. Quiles y R. Rodríguez-Varo (Eds.), Arquitectura vernácula en el mundo ibérico: actas del congreso internacional sobre arquitectura vernácula (pp. 151-159). Universidad Pablo de Olavide.

Sulé, J. (2016, 14 de abril). La rebelión de un vecindario. El País. https://elpais.com/elpais/2016/04/14/ album/1460648740_768815.html\#foto_gal_1

Torres, G. M. (2014). Vivienda y arquitectura tradicional en el Pacífico colombiano: Patrimonio cultural afrodescendiente. Universidad del Valle.

Torres, G. M. y Gniset, J. A. (2006). Hábitats y sociedades del Pacífico. Aldeas de la costa de Buenaventura (Vol. 3). Universidad del Valle.

Villabona, E. L. (2020). Valoración de las técnicas constructivas ancestrales del pueblo Makaguán (tesis de maestría). Universidad Nacional de Colombia, Medellín, Colombia. https://repositorio.unal.edu.co/ handle/unal/76827 